\title{
Traumberuf Füsotherapeut
}

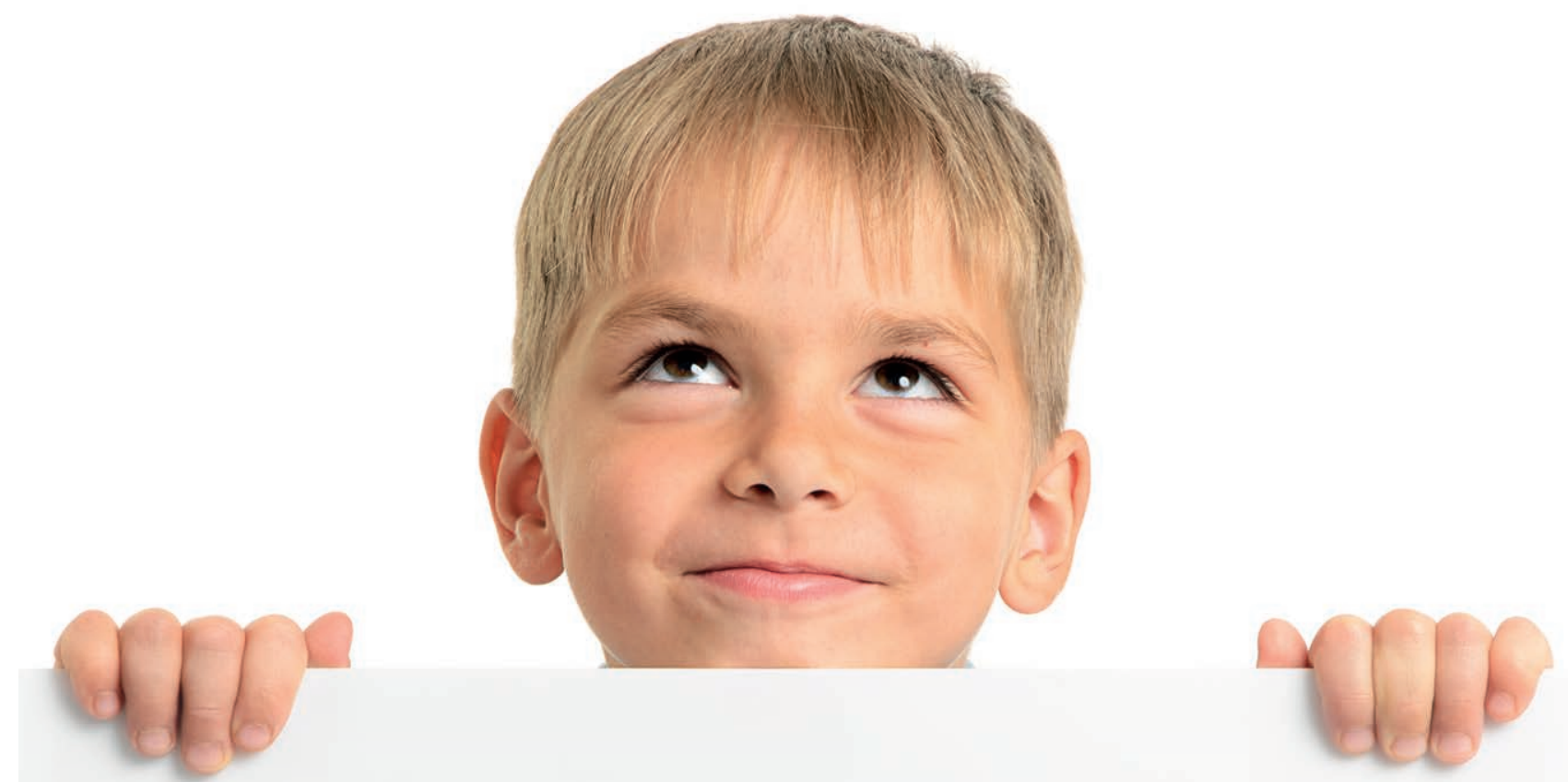

- Die richtige Motivation ist einfach alles. Diese Erfahrung durfte ich jüngst während eines Besuches beim internationalen Tennisturnier in Stuttgart machen. Gute Stimmung, hochkarätige Athleten und Fans von Jung bis Alt. Ein Winzling von etwa vier Jahren war auf dem Sitz neben mir besonders interessiert. Sein T-ShirtAufdruck verriet: ein Roger-Federer-Fan.

_ Auf dem Center-Court ging es heiß her, als sich eine Spielerin von Krämpfen geplagt an die Wade griff - Auszeit für eine kurze Behandlung. Der Physiotherapeut war sofort zur Stelle. „Mama, wer ist das und was macht der da?“, will der interessierte Junge wissen. „Das ist ein Physiotherapeut, mein Schatz, die behandeln die Sportler, wenn sie Schmerzen haben. Und wenn die Behandlung fertig ist, sind die Schmerzen weg und die Tennisspieler können weiterspielen. “Die Augen des Kleinen begannen zu leuchten. Seine Chance witternd, wollte er weiter wissen: „Hat Roger Federer auch schon so einen?“ „Ich denke doch, ja“, schmunzelt die Mutter in meine Richtung. „Egal“, erwidert der Kleine unbeirrt, „ich will trotzdem Füsotherapeut werden.“

_ Wer einst auch so Feuer und Flamme für unseren Beruf war, ist heute zunehmend enttäuscht über die schlechten Rahmenbedingungen. Die Erwartung an das viel diskutierte Positionspapier von Roy Kühne (๑ S. 10) ist groß. Damit sich Arbeitsbedingungen und Vergütung verbessern, braucht es aber Therapeuten, die, wie der kleine Tennis-Fan, weiter an ihren Zielen festhalten und dafür kämpfen, dass der Beruf ein Traumberuf bleibt.
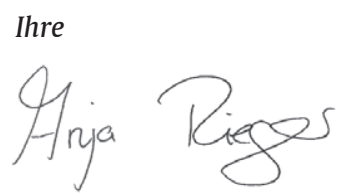

\section{ZU GEWINNEN}

In jeder physiopraxis werden attraktive Gewinne verlost. Möchten Sie einen ergattern, klicken Sie unter www.thieme.de/physiopraxis auf „Gewinnspiel“. Und das gibt es in dieser Ausgabe zu gewinnen:

Bücher: 3mal „Heilmittelrichtlinie mit extrabudgetären Verordnungen“ Seite 8, 2mal „Sportosteopathie“ Seite 24, $1 \mathrm{mal}$ „Klinische Muster in der Manuellen Therapie“ Seite 29, 1 mal „Angewandte Physiologie: Band 1“ Seite 31,

2mal „Die neue Rückenschule“ Seite 39, 2mal „Gehen verstehen“ Seite 56 